\title{
Prevalence, Characteristics, and In-Hospital Outcomes of Metabolic Syndrome among Patients with Acute Coronary Syndrome in the United Arab Emirates
}

\author{
Abdulla Shehab ${ }^{1, \#, *}$, Bayan Al-Dabbagh ${ }^{1, \#}$, Wael Almahmeed ${ }^{2}$, Nazar Bustani ${ }^{2}$, Nicolaas \\ Nagelkerke ${ }^{3}$, Abdulla Alnaeemi ${ }^{4}$ and Alawi A. Alsheikh-Ali ${ }^{2,5}$ \\ ${ }^{1}$ Department of Internal Medicine, Faculty of Medicine and Health Sciences, United Arab Emirates University, United \\ Arab Emirates \\ ${ }^{2}$ Heart and Vascular Institute, Sheikh Khalifa Medical City, Abu Dhabi, United Arab Emirates \\ ${ }^{3}$ Department of Community Medicine, Faculty of Medicine and Health Sciences, United Arab Emirates University, Unit- \\ ed Arab Emirates \\ ${ }^{4}$ Zayed Military Hospital, Abu Dhabi, United Arab Emirates \\ ${ }^{5}$ Tufts Clinical and Translational Science Institute, Tufts Medical Center, Boston, MA, USA
}

\begin{abstract}
Objective: To evaluate clinical profiles, management and in-hospital outcomes of acute coronary syndrome (ACS) patients with metabolic syndrome (MetS) in the United Arab Emirates (UAE).

Methods: MetS was defined according to the criteria for its diagnosis by the International Diabetes Federation (IDF) and the American Heart Association/National Heart, Lung and Blood Institute (AHA/NHLBI). Participants were admitted to various hospitals in the UAE with a diagnosis of ACS in 2007 as part of the Gulf Registry of Acute Coronary Events (Gulf RACE) project. We compared baseline characteristics, treatment patterns, and in-hospital outcomes stratified by MetS status.

Results: Of 1259 patients with ACS in the UAE (mean age: $52 \pm 11$ years, $88.8 \%$ males), the majority $(\mathrm{n}=851,67.6 \%)$ had MetS. MetS patients were more frequently males (86.4 vs $13.6 \% ; P<0.001)$. They were more obese (waist circumference and BMI, $P<0.001)$ as compared with non-MetS patients. MetS was more frequently associated with hypertension (51.1 vs 37.7\%; $P<0.001)$ and diabetes mellitus (45.6 vs $24.3 \% ; P<0.001)$. After multivariate adjustment, certain MetS criteria rather than MetS itself were associated with higher in-hospital mortality and heart failure. Paradoxically, hypertension was associated with lower in-hospital mortality.
\end{abstract}

Conclusions: Prevalence of MetS among patients with ACS in our study population was high. Certain MetS criteria were associated with higher in-hospital mortality and heart failure.

Keywords: acute coronary syndrome, Gulf Registry of Acute Coronary Events, metabolic syndrome, Middle East, obesity, United Arab Emirates.

\section{INTRODUCTION}

Metabolic syndrome (MetS) is a cluster of cardiovascular disease risk factors characterized by abdominal obesity, raised fasting blood glucose, elevated triglycerides, reduced high density lipoprotein cholesterol (HDL-C) and hypertension $[1,2]$. MetS has been defined by different diagnostic criteria [3-6]. This is partly due to the absence of a "gold standard" diagnostic test which in turn reflects conceptual vagueness, including a lack of clarity about which pathophysiological processes reflect a common underlying

\footnotetext{
*Address correspondence to this author at the Department of Internal Medicine, Faculty of Medicine \& Health Sciences, PO Box 17666, UAE University, Al Ain, UAE; Tel: + 9713-7137491; Fax: + 9713-7672995;

E-mail: a.shehab@uaeu.ac.ae

"these authors contributed equally to this work.
}

"syndrome". In fact, the very existence of a single "syndrome"has been challenged [7]. Recently, other abnormalities such as chronic proinflammatory and prothrombotic states, non-alcoholic fatty liver disease and sleep apnea have been added to the entity of the syndrome, making its definition even more involved. Nevertheless, the International Diabetes Federation (IDF) and the American Heart Association/National Heart, Lung, and Blood Institute (AHA/NHLBI) recently proposed a common definition [8] and nosological issues and controversies have not diminished interest in the condition. Not least, perhaps, because the prevalence of the MetS phenotype is rapidly increasing worldwide, in children and adolescents in particular, this will surely increase the cardiovascular disease burden.

MetS is a complex condition with high socioeconomic cost that is rapidly increasing in prevalence worldwide as a 
consequence of the global "epidemics" of obesity and sedentary lifestyles [9]. The Third National Health and Nutritional Survey (NHANES III) estimated that MetS affected $25 \%$ of adults in the United States (US) [10]. Furthermore, it has a substantial impact on developing cardiovascular disease (CVD) and type 2 diabetes mellitus (T2DM). MetS patients are at high risk of coronary heart disease (CHD) in addition to morbidity and mortality [11-14]. Not surprisingly therefore, considerable evidence shows that MetS is highly prevalent among patients with Acute Coronary Syndrome (ACS) $[15,16]$ and has also been associated with poor in-hospital prognosis [17-19].

In the present study, we analyze the prevalence, characteristics and in-hospital outcomes of MetS and its components among ACS patients in the United Arab Emirates (UAE).

\section{METHODS}

\section{Patients and Data Collection}

Patients were selected from the Gulf Registry of Acute Coronary Events (Gulf RACE), a prospective multinational, multicentre registry of patients above 18 years of age hospitalized with the final diagnosis of ACS from various hospitals in 6 Middle Eastern countries [20]. Details of the Gulf RACE have been previously described [20]. There were no exclusion criteria and recruitment in the pilot phase started from May 8, 2006, to June 6, 2006. Enrolment in the next phase of the registry started in January 29, 2007, and continued until June 29, 2007. The present study included 1259 of 1697 patients hospitalized with an ACS across 18 hospitals in the UAE with complete data on MetS parameters and were stratified into those with $(851,67.6 \%)$ and without MetS $(408,32.4 \%)$. These hospitals care for more than $85 \%$ of patients with ACS in the country. Demographic, historical, and clinical data as well as in-hospital outcomes were recorded by study physicians for all patients admitted with a diagnosis of ACS. Outcome parameters evaluated during the hospital stay included in-hospital mortality, recurrent ischemia/reinfarction, heart failure (HF) and cardiogenic shock.

\section{Definition of MetS}

Patients with ACS were categorized according to the presence or absence of MetS at baseline, using the recent unified definition of the IDF and the AHA/NHLBI [8]. Patients with 3 or more of the following 5 criteria were regarded as having MetS.

1. Abdominal obesity: waist circumference of $\geq 94 \mathrm{~cm}$ for men and $\geq 80 \mathrm{~cm}$ for women for Middle Eastern (Mediterranean/European) populations.

2. Elevated triglycerides of $\geq 150 \mathrm{mg} / \mathrm{dl}(1.7 \mathrm{mmol} / \mathrm{l})$ or patient on specific drug treatment.

3. Reduced HDL-C of $<40 \mathrm{mg} / \mathrm{dl}(1.0 \mathrm{mmol} / \mathrm{l})$ for males and $<50 \mathrm{mg} / \mathrm{dl}(1.3 \mathrm{mmol} / \mathrm{l})$ in females or patient on specific drug treatment.

4. Elevated $\mathrm{BP} \geq 130 \mathrm{mmHg}$ for systolic and/or $\geq 85$ $\mathrm{mmHg}$ for diastolic or patient on specific antihypertensive drug treatment.
5. Elevated fasting blood glucose of $\geq 100 \mathrm{mg} / \mathrm{dl}(\geq 5.6$ $\mathrm{mmol} / \mathrm{l}$ ) or patient on specific drug treatment.

Definitions of the sets of variables collected from the patients, outcome parameters as well as the diagnosis of ACS types were carried out following the American College of Cardiology clinical data standards [21]. Smokers were defined as smoking cigarettes or sheesha (water pipe) within 1 month prior to index admission. A positive family history of CHD was defined as evidence of this disease in a parent, sibling, or children before the age of 55 years. Each participating hospital received approval from their local hospital ethics committee or institutional review board.

\section{Statistical Analysis}

All data were analyzed with SPSS statistical software version 18.0 (Chicago, Illinois, USA). The comparison of continuous variables between patients with and without MetS was performed using the Student t-test. Categorical variables were expressed by frequency distribution and were compared using the Pearson's chi-square tests (or Fisher exact test for cells less than 5). Continuous variables with normal distribution were expressed as mean $\pm \mathrm{SD}$. Univariate and multivariable logistic regression analysis was performed to evaluate the association, as expressed by odds ratios (OR), between MetS, as well as its 5 constituent criteria, with in-hospital outcomes (specifically in-hospital mortality and heart failure) while adjusting for age, gender and smoking status. Furthermore, we determined the frequency of each MetS criteria in the study cohort stratified by gender. In all cases a two-sided P-value below 0.05 was considered significant.

\section{RESULTS}

The records of 1259 ACS patients represent the total sample of this study. The clinical and metabolic characteristics of the study sample, by MetS diagnosis, are shown in Table 1. The mean age of the cohort was $52 \pm 11$ years, ranging from 22 to 100 years. The ages of the patients with and without MetS (Table 1) were not significantly different (52 \pm 11 vs $52 \pm 12$ years; $\mathrm{P}=0.62)$. The majority of the patients were males $(\mathrm{n}=1118,88.8 \%)$. Nevertheless, the prevalence of MetS was much higher and decreased with age in females compared with males (Fig. 1). As expected, the MetS patients were often obese, hypertensive, diabetic, with high BMI values and waist circumference measurements $(\mathrm{P}<$ 0.001 for all comparisons).

MetS was associated with higher total cholesterol $(4.7 \pm$ 1.5 vs $4.3 \pm 1.6 \mathrm{mmol} / 1 ; \mathrm{P}<0.001)$, low-density lipoprotein cholesterol $(3.3 \pm 1.3$ vs $3.1 \pm 1.4 \mathrm{mmol} / \mathrm{l} ; \mathrm{P}=0.045)$, and triglycerides $(2.3 \pm 1.6$ vs $1.9 \pm 1.9 \mathrm{mmol} / \mathrm{l} ; \mathrm{P}=0.001)$ but lower HDL-C levels $(1.0 \pm 0.5$ vs $1.2 \pm 0.7 \mathrm{mmol} / 1 ; \mathrm{P}<$ $0.001)$. However, history of stroke (3.2 vs $5.9 \%$; $\mathrm{P}=0.022)$ was less frequent among patients with MetS. \#There were no significant differences between the 2 groups in reported history of hyperlipidemia, family history of CHD or renal impairment.

Table 2 outlines the in-hospital management of patients. Overall, both groups equally received aspirin, clopidogrel, heparin and glycoprotein IIb/IIIa antagonists and were more 
Table 1. Demographic and Baseline Characteristics of the Studied ACS Patients Stratified by Metabolic Syndrome Status $(\mathbf{n}=1259)$.

\begin{tabular}{|c|c|c|c|}
\hline Variable & MetS $(n=851)$ & Non-MetS $(n=408)$ & $\boldsymbol{P}$ \\
\hline Age, mean $\pm \mathrm{SD}$, years & $52 \pm 11$ & $52 \pm 12$ & 0.626 \\
\hline Waist circumference, mean $\pm \mathrm{SD}, \mathrm{cm}$ & $93 \pm 16$ & $82 \pm 16$ & $<0.001$ \\
\hline Body mass index, mean $\pm \mathrm{SD}, \mathrm{kg} / \mathrm{m}^{2}$ & $27.4 \pm 4.5$ & $24.6 \pm 3.5$ & $<0.001$ \\
\hline Hyperlipidemia & $311(36.5 \%)$ & $134(32.8 \%)$ & 0.208 \\
\hline Diabetes mellitus & $388(45.6 \%)$ & $99(24.3) \%$ & $<0.001$ \\
\hline Current smoker (including sheesha) & $413(48.5 \%)$ & $218(53.4 \%)$ & 0.105 \\
\hline Family history of CAD & $152(17.9 \%)$ & $65(15.9 \%)$ & 0.426 \\
\hline COPD & $29(3.4 \%)$ & $10(2.5 \%)$ & 0.391 \\
\hline History of stroke & $27(3.2 \%)$ & $24(5.9 \%)$ & 0.031 \\
\hline PAD & $20(2.4 \%)$ & $12(2.9 \%)$ & 0.568 \\
\hline ACS diagnosis: & & & 0.095 \\
\hline Non-STEMI & $196(23.1 \%)$ & $86(21.2 \%)$ & \\
\hline STEMI & $363(42.8 \%)$ & $185(45.6 \%)$ & \\
\hline LBBB MI & $4(0.5 \%)$ & $4(1.0 \%)$ & \\
\hline UA & $228(26.9 \%)$ & $94(23.2 \%)$ & \\
\hline LDL-C, $(\mathrm{mmol} / \mathrm{l})$ & $3.3 \pm 1.3$ & $3.1 \pm 1.4$ & 0.045 \\
\hline HDL-C, $(\mathrm{mmol} / \mathrm{l})$ & $1 \pm 0.5$ & $1.2 \pm 0.7$ & $<0.001$ \\
\hline Triglyceride, $(\mathrm{mmol} / \mathrm{l})$ & $2.3 \pm 1.6$ & $1.9 \pm 1.9$ & 0.001 \\
\hline
\end{tabular}

MetS = metabolic syndrome; $\mathrm{SD}$ = standard deviation; $\mathrm{CAD}=$ coronary artery disease; $\mathrm{MI}=$ myocardial infarction; $\mathrm{PCI}=$ percutaneous coronary intervention; $\mathrm{CABG}=$ coronary artery bypass surgery; $\mathrm{COPD}=$ chronic obstructive pulmonary disease; $\mathrm{PAD}=$ peripheral arterial disease; Non-STEMI = non-ST-segment elevation myocardial infarction; STEMI = ST-segment elevation myocardial infarction; LBBB = left bundle branch block; UA = unstable angina; LDL-C= low-density lipoprotein cholesterol; HDL-C= high-density lipoprotein cholesterol.

likely to receive low molecular weight heparin than unfractionated heparin. Further, patients with MetS were more likely to be treated with beta-blockers (74.1 vs $64.6 \%$; $=$ 0.001 ), angiotensin-converting enzyme (ACE) inhibitors (72.4 vs $65.7 \% ; \mathrm{P}=0.016)$, calcium channel blockers $(10.1$ vs $5.7 \%$; $\mathrm{P}=0.008)$, statins $(96.8$ vs $93.9 \%$; $\mathrm{P}=0.022)$, nitrates $(74.4$ vs $63.3 \% ; \mathrm{P}<0.001)$ and subcutaneous insulin (39.5 vs $20.3 \%$; $\mathrm{P}<0.001)$. High prevalence of diabetes mellitus ( $\mathrm{n}=388,45.6 \%)$ among the MetS group of patients was evident in comparison to the non-MetS group $(\mathrm{n}=99$, $24.3 \%$ ).
The prevalence of the different components of MetS abnormalities of the ACS population was stratified by gender (Table 3). The most prevalent MetS abnormality was hypertension (71.4\%) followed by low HDL-C (71\%). Around two-thirds of the cohort $(67 \%)$ had high fasting blood glucose while hypertriglyceridimia and abdominal obesity were present in $48.3 \%$ and $45.2 \%$ of the study cohort, respectively. The latter percentages are similar in the male population given their preponderance in the study. The table also shows that the most common MetS abnormality in females was low HDL-C (83.7\%) followed by abdominal obesity $(80.9 \%)$. 


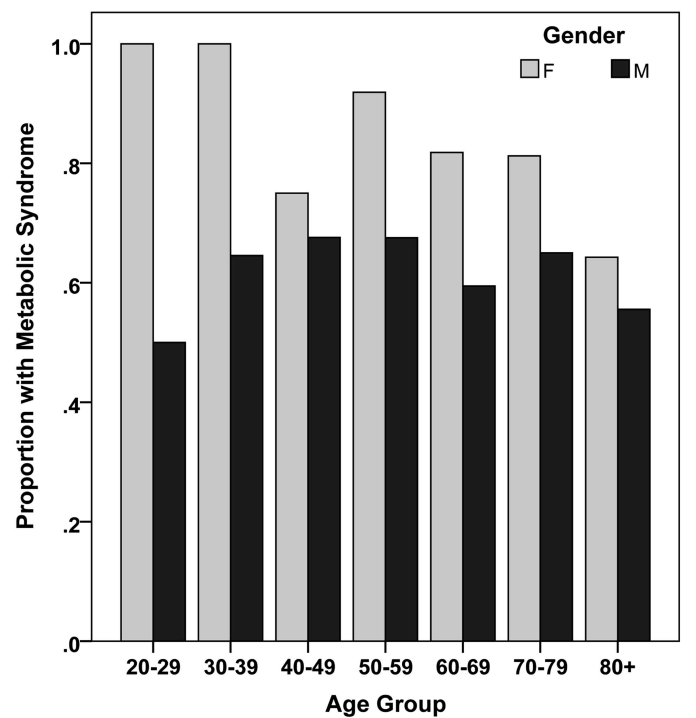

Fig. (1). Proportion of metabolic syndrome in the study cohort stratified according to age and gender $(\mathrm{n}=1259)$.

Table 2. In-hospital Management of the Studied ACS Patients with and Without MetS (n = 1259)

\begin{tabular}{|l|c|c|c|}
\hline \multicolumn{1}{|c|}{ In-hospital management } & MetS (n= 851) & Non-MetS (n= 408) & $401(98.3 \%)$ \\
\hline \hline Aspirin & $846(99.4 \%)$ & $397(97.3 \%)$ & 0.066 \\
\hline Clopidogrel & $834(98 \%)$ & $61(15 \%)$ & 0.421 \\
\hline IV HEP & $125(14.7 \%)$ & $356(87.3 \%)$ & 0.932 \\
\hline LMW HEP & $736(86.5 \%)$ & $158(38.7 \%)$ & 0.790 \\
\hline GP & $370(43.6 \%)$ & $263(64.6 \%)$ & 0.100 \\
\hline BB & $631(74.1 \%)$ & $268(65.7 \%)$ & 0.001 \\
\hline ACE & $615(72.4 \%)$ & 0.018 \\
\hline AIIRB & $35(4.1 \%)$ & $23(5.7 \%)$ & 0.261 \\
\hline CCB & $86(10.1 \%)$ & $383(93.9 \%)$ & 0.007 \\
\hline Statins & $824(96.8 \%)$ & $259(63.3 \%)$ & $83(20.3 \%)$ \\
\hline Nitrates & $633(74.4)$ & $4(1.0 \%)$ & $<0.001$ \\
\hline SQ INS & $335(39.5 \%)$ & $<0.001$ \\
\hline IV INS & $15(1.8 \%)$ & 0.334 \\
\hline
\end{tabular}

MetS = metabolic syndrome; IV HEP = intravenous heparin; LMW HEP = low molecular weight heparin; GP = glycoprotein IIb/IIIa inhibitors; $\mathrm{BB}=$ beta-blockers; ACE $=$ angiotensin-converting enzyme inhibitors; AIIRB = angiotensin II receptor blockers; $\mathrm{CCB}=$ calcium channel blockers; SQ Insulin = subcutaneous insulin; IV Insulin = intravenous insulin.

Univariate and stepwise multivariable logistic regression with backward selection was done to determine the relationship between MetS and in-hospital outcomes (mortality and heart failure). Even after controlling for age, gender and smoking status, MetS was not a significant predictor for either of the chosen in-hospital outcomes: mortality $(\mathrm{P}=0.11)$ and heart failure $(\mathrm{P}=0.84)$. To explore whether this implied that none of the MetS constituent criteria was associated with these outcomes we repeated the logistic regression by further inclusion of the 5 MetS criteria as well as age, gender and smoking status as covariables (Table 4).

Table 4 indicates that after inclusion of the five MetS factors in the model, high blood glucose was the only significant MetS factor to be correlated with in-hospital HF.
Specifically, patients with hyperglycemia were 1.71 times $(\mathrm{OR}=1.71 ; 95 \% \mathrm{CI}: 1.16-2.53 ; \mathrm{P}=0.006)$ more likely to encounter HF than those with low blood glucose. Furthermore, the model also showed that in-hospital mortality was positively associated with those patients having high blood sugar $(\mathrm{OR}=6.49 ; 95 \% \mathrm{CI}: 1.13-37 ; \mathrm{P}=0.035)$, and negatively with elevated $\mathrm{BP}(\mathrm{OR}=0.11 ; 95 \% \mathrm{CI}$ : $0.03-0.42 ; \mathrm{P}=$ 0.001). Low HDL-C ( $\mathrm{P}=0.027)$ (Table 4) was also significant.

\section{DISCUSSION}

This study reveals a high prevalence of MetS among a group of patients with ACS in the UAE (more so in males 
Table 3. The Frequency (\%) of Each Inclusion Component of the MetS in the Study Cohort (n= 1259) Stratified by Gender

\begin{tabular}{|l|c|c|c|}
\hline \multicolumn{1}{|c|}{ MetS criteria } & Total & Men & Women \\
\hline \hline Abdominal obesity & $569(45.2 \%)$ & $455(40.7 \%)$ & $114(80.9 \%)$ \\
\hline High triglyceride & $608(48.3 \%)$ & $540(48.3 \%)$ & $68(48.2 \%)$ \\
\hline Low HDL-C & $894(71.0 \%)$ & $776(69.4 \%)$ & $118(83.7 \%)$ \\
\hline Hypertension & $899(71.4 \%)$ & $790(70.7 \%)$ & $109(77.3 \%)$ \\
\hline High blood sugar & $844(67 \%)$ & $752(67.3 \%)$ & $92(65.2 \%)$ \\
\hline
\end{tabular}

MetS = metabolic syndrome; HDL-C = high-density lipoprotein cholesterol.

Table 4. Relationship between MetS and Different In-hospital Outcomes Using Multivariable Logistic Regression

\begin{tabular}{|l|c|c|c|c|c|c|}
\hline \multirow{2}{*}{ Criteria } & \multicolumn{3}{|c|}{ Heart Failure } & \multicolumn{3}{c|}{ Mortality } \\
\cline { 2 - 7 } & OR & $\mathbf{9 5 \% ~ C I ~}$ & P & OR & 95\% CI & $1.02-1.13$ \\
\hline \hline Age & 1.04 & $1.03-1.06$ & $<0.001$ & 1.07 & 0.004 \\
\hline Gender (Male) & 0.48 & $0.30-0.79$ & 0.004 & 0.18 & $0.047-0.72$ & N/A \\
\hline Low HDL-C* & & & & 0.016 & 0.027 \\
\hline Hypertension & & & & 0.11 & 0.001 \\
\hline High blood sugar & 1.71 & $1.16-2.53$ & 0.006 & 6.49 & $1.13-37$ \\
\hline
\end{tabular}

$\mathrm{OR}=$ odds ratio; $\mathrm{CI}=$ confidence interval; HDL-C $=$ high-density lipoprotein cholesterol; N/A = not applicable.

The variables that were dropped out of the multivariable logistic regression using the stepwise-backward elimination method included smoking, hypertriglyceridemia and abdominal obesity.

* In the case of in-hospital mortality, the odds ratio for low HDL-C was infinite, due to one of the cells being zero [38].

which represented $88.8 \%$ of the study population). The prevalence of MetS in our study $(67.6 \%)$ was very similar to the $66 \%$ recently reported for an ACS population in Oman [22]. The high prevalence of MetS (46\%) among ACS patients in 6 Middle Eastern countries including the Gulf and the UAE has been recently demonstrated [23] and reflects both the high risk of ACS among MetS patients and the high prevalence of MetS in these populations due to sedentary lifestyle, lower health awareness and higher income. Our results are not surprising in view of the high and rising rates of obesity and MetS in the Gulf countries [24, 25]. In the entire Gulf RACE cohort, $67 \%$ of patients were overweight or obese, were more likely to be female and have diabetes, hypertension and dyslipidemia [24]. MetS was diagnosed in 51\% of 1108 patients of French-Canadian origin with CHD symptoms [26]. In our study, hypertension (71.4\%) and low HDL$\mathrm{C}(71 \%)$ were the most common metabolic abnormalities; followed by high blood glucose $(67 \%)$. These values are higher than those previously reported by others. In particular, the prevalence of low HDL-C in the entire GULF RACE cohort and in the population from Oman has been demonstrated $[27,28]$.

While MetS and its components have consistently been associated with ACS, we found that once ACS developed, MetS per se did not correlate with in-hospital mortality and $\mathrm{HF}$. An important result was that hyperglycemia $(\mathrm{OR}=1.71$; 95\% CI: $1.16-2.53 ; \mathrm{P}=0.006$ ) was the only component of MetS associated with increased risk of in-hospital HF. This finding is in agreement with recently published results [22]. The importance of hyperglycemia on outcome of ACS pa- tients is further illustrated by the findings that increased risk of death in both diabetic [29] and nondiabetic subjects [30] has been associated with high blood glucose levels which is rather common in patients admitted with acute myocardial infarction (AMI). Moreover, it has been demonstrated that MI patients with impaired fasting blood glucose had a higher risk of developing cardiogenic shock during their hospital stay [31].

Similarly, we also found that high blood glucose was associated $(\mathrm{OR}=6.49 ; 95 \% \mathrm{CI}: 1.13-37 ; \mathrm{P}=0.035)$ with inhospital mortality. In addition, low HDL-C was also a contributing risk factor $(\mathrm{P}=0.027$; $\mathrm{OR}=$ Infinite; $\mathrm{cf}$ Table 4). It has been shown that low HDL-C is the most common type of dyslipidemia found in patients with CHD [32]. Surprisingly, hypertension was also significantly associated but was protective against in-hospital mortality $(\mathrm{OR}=0.11 ; 95 \% \mathrm{CI}$ : $0.03-0.42 ; \mathrm{P}=0.001)$. This observation could be due to the possible effect of pre-admission use of antihypertensive drugs that may be associated with better in-hospital outcomes or due to index event bias, a source of potential underestimation of causal associations [33].

Age $(\mathrm{OR}=1.04 ; 95 \% \mathrm{CI}: 1.03-1.06 ; P<0.001)$ and gen$\operatorname{der}$ (Male) $(\mathrm{OR}=0.48 ; 95 \% \mathrm{CI}: 0.30-0.79 ; P=0.004)$ were also predictors for in-hospital HF using stepwise (backward selection) logistic regression with a $4 \%$ risk increase per year of age and a $52 \%$ lower risk for males than females. In the case of in-hospital mortality, age (OR $=1.07 /$ year; $95 \% \mathrm{CI}$ : $1.02-1.13 ; \mathrm{P}=0.004)$ and gender (male) $(\mathrm{OR}=0.18 ; 95 \%$ CI: $0.047-0.72 ; \mathrm{P}=0.016)$ were also significant. As ex- 
pected, risk of adverse outcome (mortality and HF) increased with age. Interestingly, this risk was higher for females than for males. This has also been found in other studies and has been hypothesized to be due to lesser use of reperfusion techniques, diagnostic uncertainty as well as lower quality of secondary prevention and follow-up [34].

We relied on the waist circumference instead of BMI as a measure of abdominal obesity, since it has been shown to be a stronger predictor of intra-abdominal, i.e. visceral, adipose tissue [35]. Nevertheless, waist circumference was not an independent predictor of in-hospital mortality and HF, in our study, which is in agreement to previous reports $[17-19,36]$. The fact that different MetS components have different and sometimes opposite effects on mortality may well explain the lack of an association of MetS itself with mortality in this study, a finding that may cast further doubt on the existence of MetS as a meaningful nosological entity.

The strengths of this investigation include its national perspective, the complete spectrum of ACSs experienced by the large number of patients studied and the use of standardized criteria for defining ACS and hospital outcomes. However, the limitations of a registry-type study still apply, such as unidentified confounders which could influence the results. It is possible that individual studies are not representative of the whole country in which they were performed. It is also noteworthy to mention that the definition chosen to diagnose MetS also plays a role in determining MetS prevalence among study patients [37].

This study demonstrated a high prevalence of MetS in ACS patients in the UAE which was associated with hypertension and diabetes mellitus. Certain MetS constituents rather than MetS per se were associated with higher in-hospital mortality and HF. Specifically; hyperglycemia was the only significant MetS factor to be correlated with HF. Furthermore, it was also associated with in-hospital mortality along with hypertension and low HDL-C.

\section{ACKNOWLEDGEMENTS}

Gulf RACE is a Gulf Heart Association project. The authors gratefully acknowledge the financial support of Sanofi Aventis (Paris, France) and Qatar Telecommunications Company (Doha, Qatar). The sponsors had no role in study design, data collection and analysis, decision to publish, or preparation of the manuscript.

\section{CONFLICT OF INTEREST}

None declared.

\section{REFERENCES}

[1] Lakka HM, Laaksonen DE, Lakka TA, et al. The metabolic syndrome and total and cardiovascular disease mortality in middleaged men. JAMA 2002; 288: 2709-16.

[2] Malik S, Wong ND, Franklin SS, et al. Impact of the metabolic syndrome on mortality from coronary heart disease, cardiovascular disease, and all causes in United States adults. Circulation 2004; 110: $1245-50$.

[3] Alberti KG, Zimmet PZ. Definition, diagnosis and classification of diabetes mellitus and its complications. Part 1: diagnosis and classification of diabetes mellitus provisional report of a WHO consultation. Diabet Med 1998; 15: 539-53.
[4] National Cholesterol Education Program (NCEP) Expert Panel on Detection, Evaluation, and Treatment of High Blood Cholesterol in Adults (Adult Treatment Panel III) Third Report of the National Cholesterol Education Program (NCEP) Expert Panel on Detection, Evaluation, and Treatment of High Blood Cholesterol in Adults (Adult Treatment Panel III) final report. Circulation 2002; 106: 3143-421.

[5] Alberti KG, Zimmet P, Shaw J, et al. The metabolic syndrome: a new worldwide definition. Lancet 2005; 366: 1059-62.

[6] Grundy SM, Cleeman JI, Daniels SR, et al. Diagnosis and management of the metabolic syndrome: an American Heart Association/ National Heart, Lung, and Blood Institute Scientific Statement. Circulation 2005; 112: 2735-52.

[7] Kahn R. Metabolic syndrome: is it a syndrome? Does it matter? Circulation 2007; 115:1806-10.

[8] Alberti KG, Eckel RH, Grundy SM, et al. Harmonizing the metabolic syndrome: a joint interim statement of the International Diabetes Federation Task Force on Epidemiology and Prevention; National Heart, Lung, and Blood Institute; American Heart Association; World Heart Federation; International Atherosclerosis Society; and International Association for the Study of Obesity. Circulation 2009; 120: 1640-5.

[9] Grundy SM, Hansen B, Smith SC Jr, et al. Clinical management of metabolic syndrome: report of the American Heart Association/National Heart, Lung, and Blood Institute/American Diabetes Association conference on scientific issues related to management. Circulation 2004; 109: 551-6.

[10] Ford ES, Giles WH, Dietz WH. Prevalence of the metabolic syndrome among US adults: findings from the third National Health and Nutrition Examination Survey. JAMA 2002; 287: 356-9.

[11] Laaksonen DE, Lakka HM, Niskanen LK, et al. Metabolic syndrome and development of diabetes mellitus: application and validation of recently suggested definitions of the metabolic syndrome in a prospective cohort study. Am J Epidemiol 2002; 156: 1070-7.

[12] Grundy SM. Metabolic syndrome: connecting and reconciling cardiovascular and diabetes worlds. J Am Coll Cardiol 2006; 47: 1093-100.

[13] Resnick HE, Jones K, Ruotolo G, et al. Insulin resistance, the metabolic syndrome, and risk of incident cardiovascular disease in nondiabetic American Indians: the strong heart study. Diabetes Care 2003; 26: 861-7.

[14] Isomaa B, Almgren P, Tuomi T, et al. Cardiovascular morbidity and mortality associated with the metabolic syndrome. Diabetes Care 2001; 24: 683-9.

[15] Milionis HJ, Kalantzi KJ, Papathanasiou AJ, et al. Metabolic syndrome and risk of acute coronary syndromes in patients younger than 45 years of age. Coron Artery Dis 2007; 18: 247-52.

[16] Kalantzi K, Korantzopoulos P, Tzimas P, et al. The relative value of metabolic syndrome and cardiovascular risk score estimates in premature acute coronary syndromes. Am Heart J 2008; 155: 53440.

[17] Levantesi G, Macchia A, Marfisi R, et al. Metabolic syndrome and risk of cardiovascular events after myocardial infarction. J Am Coll Cardiol 2005; 46: 277-83.

[18] Zeller M, Steg PG, Ravisy J, et al. Prevalence and impact of metabolic syndrome on hospital outcomes in acute myocardial infarction. Arch Intern Med 2005; 165: 1192-8.

[19] Schwartz GG, Szarek M, Olsson AG, et al. Relation of characteristics of metabolic syndrome to short term prognosis and effects of statin therapy after acute coronary syndrome. Diabetes Care 2005; 28: 2508-13.

[20] Zubaid M, Rashed WA, Al-Khaja N, et al. Clinical presentation and outcomes of acute coronary syndromes in the gulf registry of acute coronary events (Gulf RACE). Saudi Med J 2008; 29: 251-5.

[21] Cannon CP, Battler A, Brindis RG, et al. American College of Cardiology key data elements and definitions for measuring the clinical management and outcomes of patients with acute coronary syndromes. A report of the American College of Cardiology Task Force on Clinical Data Standards (Acute Coronary Syndromes Writing Committee). J Am Coll Cardiol 2001; 38: 2114-30.

[22] Al-Rasadi K, Sulaiman K, Panduranga P, et al. Prevalence, characteristics, and in-hospital outcomes of metabolic syndrome among acute coronary syndrome patients from Oman. Angiology 2011; 62: 381-9. 
[23] Al Suwaidi J, Zubaid M, El-Menyar AA, et al. Prevalence of the metabolic syndrome in patients with acute coronary syndrome in six Middle Eastern countries. J Clin Hypertens 2010; 12: 890-9.

[24] Hadi HA, Zubaid M, Al Mahmeed W. The prevalence and outcome of excess body weight among middle eastern patients presenting with acute coronary syndrome. Angiology 2010; 61: 456-64.

[25] Mabry RM, Reeves MM, Eakin EG, et al. Gender differences in the prevalence of the metabolic syndrome in Gulf Cooperation Council Countries: systematic review. Diabet Med 2010; 27: 593-7.

[26] Solymoss BC, Bourassa MG, Campeau L, et al. Effect of increasing metabolic syndrome score on atherosclerotic risk profile and coronary artery disease angiographic severity. Am J Cardiol 2004; 93: 159-64.

[27] Al-Rasadi K, Al-Zakwani I, Zubaid M, et al. Prevalence, predictors, and impact of low high-density lipoprotein cholesterol on inhospital outcomes among acute coronary syndrome patients in the Middle East. Open Cardiovasc Med J 2011; 5: 203-9.

[28] Al-Zakwani I, Sulaiman K, Al-Rasadi K, et al. Prevalence of low high-density lipoprotein cholesterol (HDL-C) as a marker of residual cardiovascular risk among acute coronary syndrome patients from Oman. Curr Med Res Opin 2011; 27: 879-85.

[29] Fava S, Aquilina O, Azzopardi J, et al. The prognostic value of blood glucose in diabetic patients with acute myocardial infarction. Diabet Med 1996; 13: 80-3.

[30] Capes SE, Hunt D, Malmberg K, et al. Stress hyperglycemia and increased risk of death after myocardial infarction in patients with and without diabetes: a systematic overview. Lancet 2000; 355: 773-8.

[31] Zeller M, Cottin Y, Brindisi MC, et al. Impaired fasting glucose and cardiogenic shock in patients with acute myocardial infarction. Eur Heart J 2004; 25: 308-12.

[32] Alsheikh-Ali AA, Lin JL, Abourjally P, et al. Prevalence of low high-density lipoprotein cholesterol in patients with documented coronary heart disease or risk equivalent and controlled low-density lipoprotein cholesterol. Am J Cardiol 2007; 100: 1499-501.

[33] Dahabreh IJ, Kent DM. Index event bias as an explanation for the paradoxes of recurrence risk research. JAMA 2011; 23: 822-3.

[34] Thelle DS. Case fatality of acute myocardial infarction: an emerging gender gap. Eur J Epidemiol 2011; 26: 829-31.

[35] Janssen I, Heymsfield SB, Allison DB, et al. Body mass index and waist circumference independently contribute to the prediction of nonabdominal, abdominal subcutaneous, and visceral fat. Am J Clin Nutr 2002; 75: 683-8.

[36] Clavijo LC, Pinto TL, Kuchulakanti PK, et al. Metabolic syndrome in patients with acute myocardial infarction is associated with increased infarct size and in-hospital complications. Cardiovasc Revasc Med 2006; 7: 7-11.

[37] Athyros VG, Ganotakis ES, Tziomalos K, et al. Comparison of four definitions of the metabolic syndrome in a Greek (Mediterranean) population. Curr Med Res Opin 2010; 26: 713-9.

[38] Hosmer DW, Lemeshow S. Applied logistic regression. 2nd ed. New York: Wiley 2000.

(C) Shehab et al.; Licensee Bentham Open.

This is an open access article licensed under the terms of the Creative Commons Attribution Non-Commercial License (http://creativecommons.org/licenses/ by-nc/3.0/) which permits unrestricted, non-commercial use, distribution and reproduction in any medium, provided the work is properly cited. 